\title{
The Vernacular Landscape, Developing and Promoting Tourism in ChiangKhong District, Chiang Rai Province
}

\author{
Maneerat Pachankoo ${ }^{1} \&$ Zhongwei Shen ${ }^{2}$ \\ ${ }^{1}$ School of Architecture and Design, Southwest Jiaotong University, Chengdu, China \\ 2 Professor, Dean, School of Architecture and Design, Southwest Jiaotong University, Chengdu, China \\ Correspondence: Maneerat Pachankoo, School of Architecture and Design, Southwest Jiaotong University, \\ Chengdu, China. Tel: 184-0288-2319. E-mail: maneerat@swjtu.edu.cn
}

Received: January 3, 2019

Accepted: January 23, 2019

Online Published: February 28, 2019

doi:10.5539/ach.v11n1p52

URL: https://doi.org/10.5539/ach.v11n1p52

\begin{abstract}
This study comes from observing and studying about the area based strategy of change in Chiangkhong to be the city that can be balanced and stable in the midst of tourism and economic development. It focuses mainly on using the vernacular landscape. The objectives of this research are (1) to study surrounding areas and the identity of the vernacular landscape in ChiangKhong, Chiang Rai province, (2) to study about the roles of the vernacular landscape that effects the present promotion and development of tourism in ChiangKhong. The methods used in this study are reviewing literatures and related researches; including observing areas to collect data about landscape according to the meaning of the vernacular landscape and information about all 7 sub-districts about the role of landscape to tourism issues, interviewing people who are related, then analyzing and give descriptive summary. The study has shown that the vernacular landscape in ChiangKhong occurred by natural and cultural factors. All factors are connected; the Mae-Khong river, varieties of ethnic groups and Buddhism are the reasons that people's way of life, culture, tradition, and belief are influenced. Also, this caused the vernacular landscape to have a "combine" form and show the identity of "place" clearly. Bringing out the vernacular landscape to promote and support recent tourism plans can be divided into 3 categories; which includes using original assets, adapting and improving the original assets and creating new activities in forms and types of the vernacular landscape, both in hardscape and softscape.
\end{abstract}

Keywords: vernacular landscape, ChiangKhong the Green City, grobcal system

\section{Introduction}

The Vernacular Landscape is the type of landscape that represents each local identity, caused by natural factors (geography, climate, and plants), cultural factors such as habitation, life style, culture and occupations (Anambutr et al., 2006, p.1). Not only the geography of each area, people's activities are also important factors. They use local wisdom to improve natural geography and display as a creatively built environment (Limtongsakul, 2006, p.145). ChiangKhong has this asset called "Vernacular Landscape" in every sub-district.

ChiangKhong is a small district in Chaing Rai province (Chotisukhrat,2009, p.65). It is known to be a district for over 100 years, and has history of ChiangKhong community for over 1,000 years. This small city is located alongside Mae-Khong river, it connects both sides of Thailand-Laos, with the life style and cultural landscape "people-community-river basin" for a long time (Lamun, 2015, p.5). With the strengths of the area based on location, cultures, different lifestyle from varieties of ethnic groups, have made ChiangKhong become the city that is unique with an interesting landscape. However, to make ChiangKhong ready to be a tourist city is still an issue that is being discussed to find the best production and resolution. That's because most people still only use ChiangKhong as passing-through city to Laos. And ChiangKhong doesn't have clearly outstanding tourism. Thus, ChiangKhong the Star project was created to support this. This will bring out the identity, most outstanding from all 7 sub-districts in ChiangKhong to present and make ChiangKhong become a more desirable destination to visit. Therefore, the ChiangKhong development strategy plans that is called "one city two type: green City" by using vernacular landscape will help promote and support tourism (Chiang Rai area based strategy economic development plan in Chiang khong, 2017, p.10). 
This essay is the observation that comes from studying about areas development plans by focusing on studying about surrounding areas and the identity of the vernacular landscape in ChiangKhong. Including, the issues of the vernacular landscape that will help promote and develop tourism in ChiangKhong. This is to show the value of "identity" of the vernacular landscape that is very important for people and tourism in ChiangKhong.

\subsection{ChiangKhong's balance and stable development strategic plan: ChiangKhong the Green City (Lamun, 2015,} pp. 37-38).

The Green City is the idea of combining both globalization and localization together. Both can coexist as a Globcal system. The practical guideline of the Green City is focusing on area management in all dimensions, to suit with each area identity and its surrounding areas, or suit with local cultural ecology history as much as possible. All together with city plan zoning, natural resources (soil, water and forest), agriculture, fishery, tourism, culture, and lives conservation. Including, economic trading areas, and social and eco-friendly investment.

This permanent development strategic planning for ChiangKhong focuses on participatory strategic planning that comes from the local people's ideas and plans then create an Area Base Development together. This is not by using all modern or only original resources but by bringing value and uniqueness to create a new normal. It's a combination of development ideas, preservation and best management suitable for ChiangKhong. There are 4 development strategic issues which are detailed below.

The first issue, Cultural ecology and tourism by using varieties of social and cultural assets to add more value and make it permanent. The important strategy is using Landmark or social and cultural resources from the local community to study and create along with the traveling routes management, transportation and trading. This will make ChiangKhong become a "ChiangKhong Living Historical City".

The second issue, Cultural ecology for community well-being. The important strategy is announcing boundary and support "One community, one preservation" such as marine lives preservation, local forest, local culture, organic agriculture areas or natural agriculture, including restoration of natural and cultural resources.

The third issue, Local people's happiness. The important strategy is creating a "Living Learning Center" in every community to be a learning center and support a life time knowledge to local people. Including supporting their skills to add more value to their occupations.

The fourth issue, Modern economic ecology. The important strategy is developing and supporting economic and trading so as to add more value and also respect to the local culture. Goods and services must be eco-friendly.

The whole image of the project is considering original resources in each sub district, which can be summarized as details below.

(1) Rim Khong subdistrict: Tai Lue learning center and museum, natural agriculture and livestock supporting, biomaterials renewable energy learning center, and Huay Sai Man viewpoint. (2) Wiang subdistrict: Giant cat fish museum, Ban Pa Dan cultural tourism pier, agriculture products center, agricultural tourism project, Mong community, landscape viewpoint, and the ancient wooden Buddha images learning center and museum. (3) Sathan subdistrict: Fishing areas, local products center, horse sculptures. (4) Sri Don Chai subdistrict: Natural tourist attractions, the river and the Fourth Thai- Lao Friendship Bridge, sewing and offering set of yellow robes to monks ceremony by Tai Lue. (5) Huay So subdistrict: hot springs and tourist attractions for health, health care center and stadium, Chiang Rai's golden trumpet trees routes, various tribes community. (6) Khrung subdistrict: New government center, huge local forest and wetland forest, cultural tourism, and religion tourism. (7) Bun Rueang subdistrict: Chiang khong's arched entrance, wetland forest preservation, public forest areas, and infrastructure construction project.1.2 Explore Importance of the Problem

State why the problem deserves new research. For basic research, the statement about importance might involve the need to resolve any inconsistency in results of past work and/or extend the reach of a theoretical formulation. For applied research, this might involve the need to solve a social problem or treat a psychological disorder. When research is driven by the desire to resolve controversial issues, all sides in the debate should be represented in balanced measure in the introduction. Avoid animosity and ad hominem arguments in presenting the controversy. Conclude the statement of the problem in the introduction with a brief but formal statement of the purpose of the research that summarizes the material preceding it. For literature reviews as well as theoretical and methodological articles, also clearly state the reasons that the reported content is important and how the article fits into the cumulative understanding of the field. 


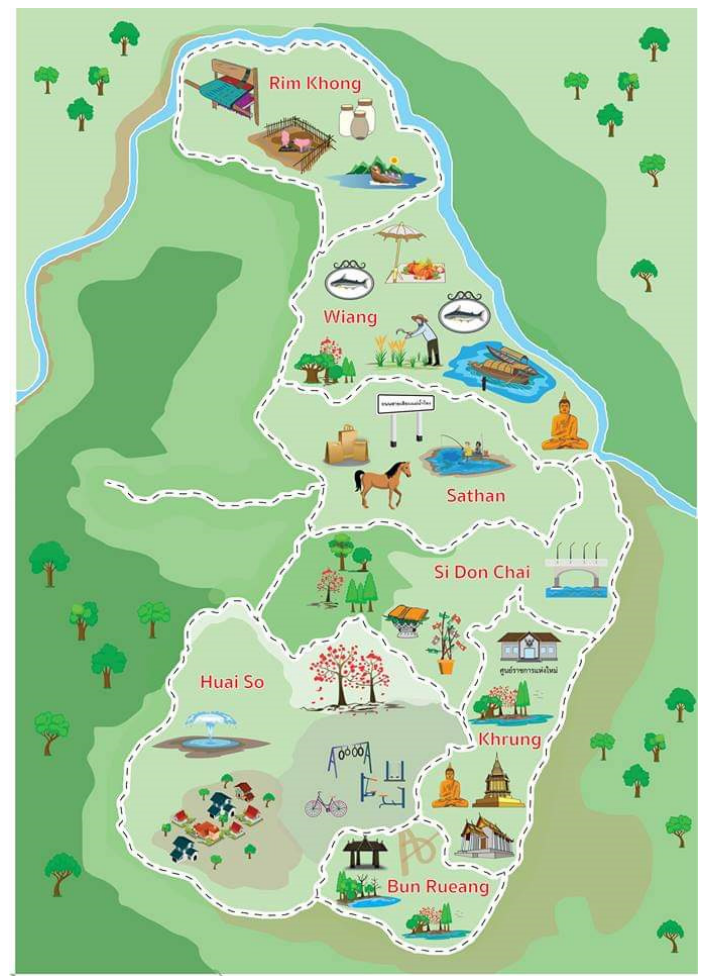

Figure 1. The whole image of the project

Source: Adapted from Lamun (2015, p.46).

\section{Research Purposes}

(1) To study surrounding areas and the identity of the vernacular landscape in ChiangKhong, Chiang Rai province.

(2) To study about the roles of the vernacular landscape that effect promoting and developing tourism in ChiangKhong at the present time.

\section{Method}

\subsection{Review basic literature data and related researches before field data}

Review basic literature data and related researches before field data collection such as, document about vernacular landscape, ChiangKhong's balance and stable development strategic plan: ChiangKhong the Green City, including information about areas in ChiangKhong, Chiang Rai province.

\subsection{Field data collection}

Field data collection, observing the whole image from all 7 sub-districts in ChiangKhong, there are Wiang, Sathan, Khrueng, Bun Rueang, Huai so, Si Don Chai and Rim Khong. The total area size is 837 square meters. To collect related data which includes:

(1) Surrounding areas and the identity of the vernacular landscape in ChiangKhong. Observed from 2 main issues about vernacular landscape which are cultural factors (both geography and climate) and plants. Cultural issue which are habitation/occupations, lifestyle, culture, tradition and belief. (2) The role of vernacular landscape that will help in promoting and developing tourism in ChiangKhong. Survey areas, tourists' attractions according to the Chiang Rai Special Economic Zone strategy plan and also from ChiangKhong the Green City strategy plan.

3.3 In - depth interview of two groups of people who are related to the area

They are Local government officers and specialists such as city map planners, architects, designers, local philosophers. Using the open-end question format.

3.4 Analyze data that was collected from the field data, in-depth interview, and also from literature reviews

As regards to the issues below;

(1) Analyze to find the identity of vernacular landscape in ChiangKhong, Chaing Rai province. (2) Analyze the roles of vernacular landscape that will help in promoting and developing tourism in ChiangKhong at the present time. 


\subsection{Discussion and Conclusion}

\subsection{Suggestions}

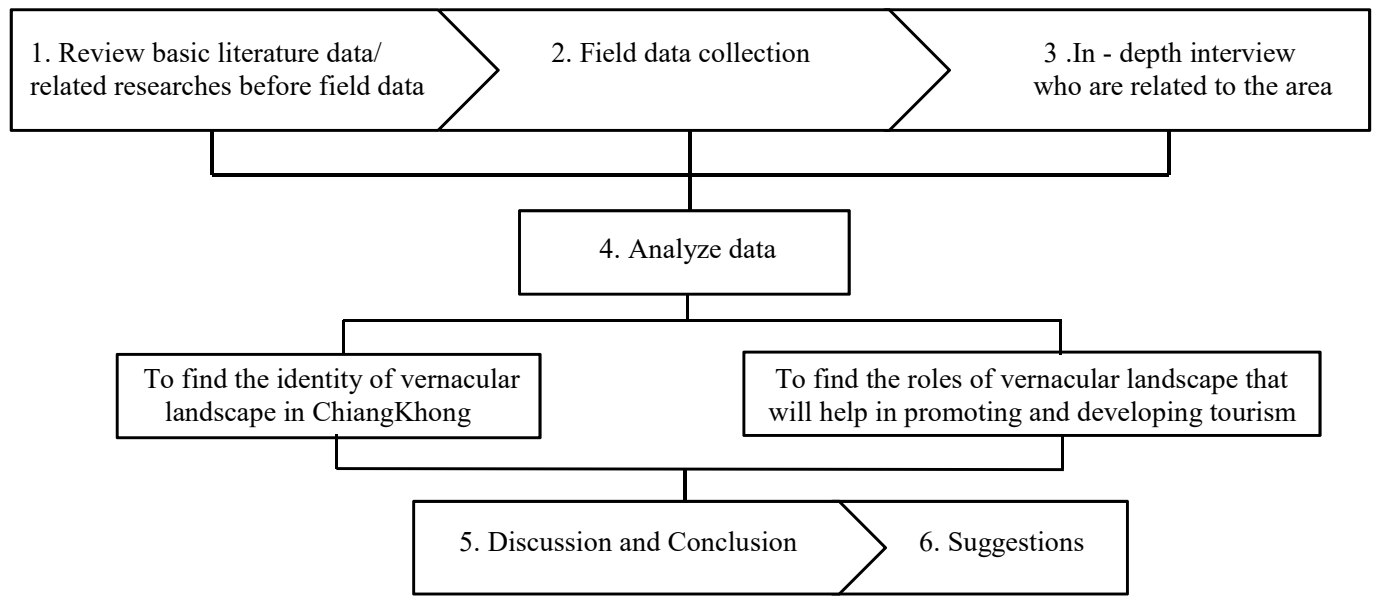

Figure 2. Methodology research mapping

\section{Results}

\subsection{The identity of the vernacular landscape in ChiangKhong, Chiang Rai province}

ChiangKhong district is a border town located in the northeast of Chiang Rai province. The boarder is connected to Laos with Mae-Khong river that has a boundary line of 42 kilometers long (Office of Natural Resources and Environmental Policy and Planning, 2014, p.2-4). The size of the district is 837 square meters (Nantasiri et al., 2017, p.11). Not only are there the Mae-Khong river and Ing river as the 2 important rivers, but there are also 10 reservoirs, 35 swamps, 35 small dams and 5 large dams. Most of the area is for agriculture and forests. The inhabitants are from varieties of ethnic groups such as, Lanna, Tai Lue, Chinese and tribesmen such as, Mong(Maew), Yao, Lahu (Musur), Khamu (Siriwong, 2015, p.5). There are 7 administrative districts. There are Wiang, Rim Khong, Sathan, Si Don Chai, Huai So, Khrueng and Bun Rueang.

According to these important assets, the identity of vernacular landscape in ChiangKhong is influenced. These factors can be categorized to 2 factors.

\section{Natural Factors}

\section{(1) Landforms}

The geography of ChiangKhong is surrounded by high mountains in the north, east and west. And low land form in the middle. It is made up of 2 rivers namely; Mae-Khong river and Ing river. It has a long distance of low land or forests (Siriwong, 2015, p.5), wetland that is the detention basin called "Kame Ling". And it is also an important natural resources learning center for local people. Around the mountain area is from 340 meters high to 1,420 meters high above medium sea level (Office of Natural Resources and Environmental Policy and Planning, 2014, pp. 2-5).

With the landscape of mountains, hills, low land, alluvial plains and rivers makes it has beautiful natural landscape. For example, Rim Khong sub-district area, the beautiful scenery of roads along the Mae-Khong river between ChiangKhong-Mae Sai, and a beautiful view of the river and mountains around the river. Or in Huai So subdistrict, Ing river meets Mae-Khong river makes the two colored river. In Wiang sub- district, has an interesting slope geomorphology along Mae- Khong river, and beautiful beach stretches along the Mae-Khong river.

\section{(2) Climate}

The climate in all 7 sub- districts in ChiangKhong is tropical savannah (according to Koppen's system) Influenced by southwest monsoon and northeast monsoon, also influenced by low pressure and tropical storms from the South China Sea. Because of the landscape with most mountains and forests, the climate is very different for each season. There are 3 seasons, which are summer between March-mid May. Then The climate is hot and humid with highest temperature of 36 degree Celsius. In therainy season between May-October. The heaviest rain falls during August-September, the highest rainfall is 168 millimeters and approximately 1,853 millimeters per year. Winter or 
dry season, between mid-October- February, the temperature is cold and the lowest temperature is around 2 degree Celsius (Office of Natural Resources and Environmental Policy and Planning, 2014, pp.2-31,2-32).

The differences of the climate in each season in ChiangKhong is very clear. It affects physical activity and activity in the area that changes in each season such as, agriculture, fishing, lifestyle, clothes. Moreover, those seasons cause water level, effect the landscape along the river shore especially, around Mae-Khong river. From the survey it was found out that in rainy season, water level is too high to plant anything along the riverside.

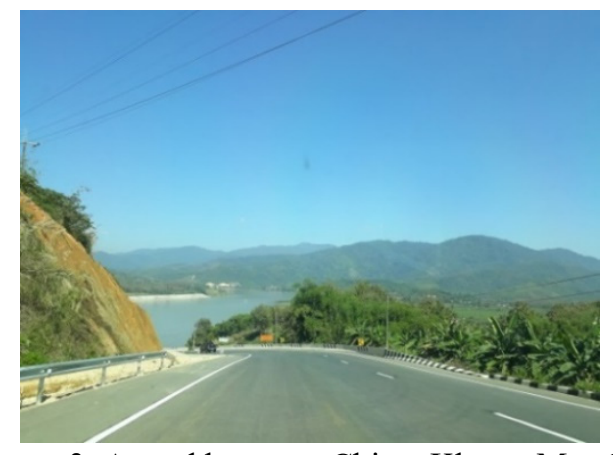

Figure 3. A road between ChiangKhong-Mae Sai

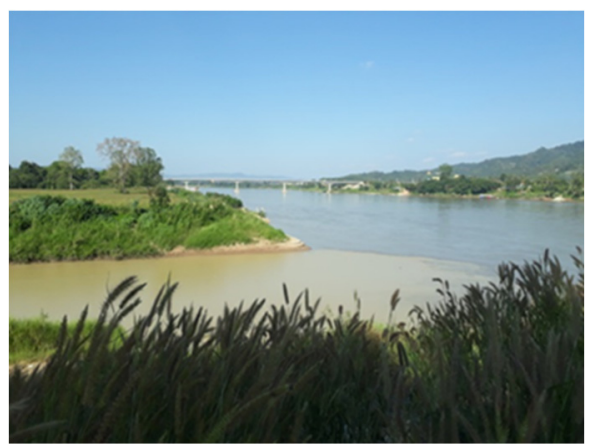

Figure 4. Two colored river

\section{(3) Vegetation}

Vegetation in ChiangKhong depends on area landscape, as detailed below.

(3.1) Around the mountains and high land are abundantly mixed deciduous forests. $47.41 \%$ of forest and national reserved forest are located in ChiangKhong. There are 5 forests which are Mae- Khong forest situated on the right. Doi Khamin and Nam-Yaeng forest, Nam-mah and nam-chang forest, Doi-Luang forest, Nam-Yao and Nam-So forest, Nam-Mae-Ing-Mae-Ngao forest. Most plants around these areas are burma padauk, teak, canarium subulatum, shorea obtusa, burmese sal, rosewood, Indian gooseberry and bamboo (Department of Forestry Information, 2018).

(3.2) Hillsides or foothills: there are 2 zones which are forest or reserved forest and mixed forest. Most plants in this area incudes teak, rosewood, bamboo trees, and banana trees etc. Another zone is for agriculture, most plants are garden plants and farm crops or for economic purposes such as, burma padauk, rubber trees, rambutans, longans, litchis, oranges, burmese grapes, bamboos, bananas, potatoes, corns, and pineapples.

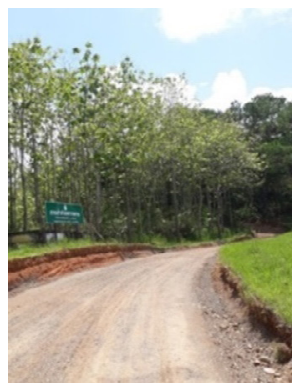

Figure 5. Forests or reserved forests

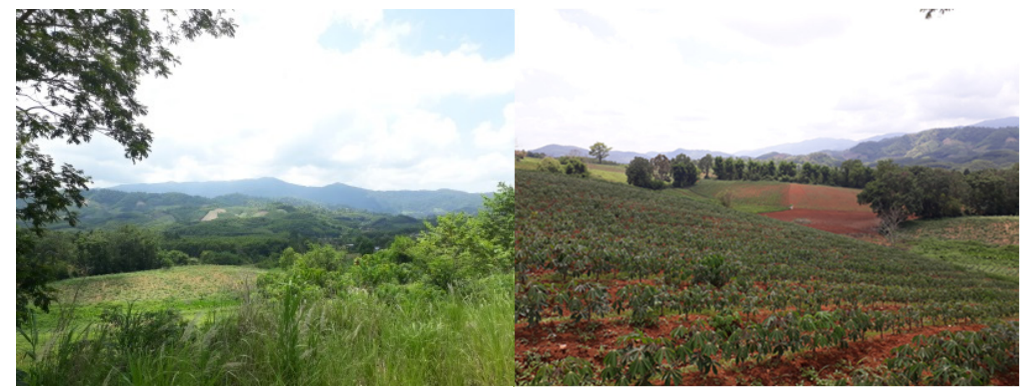

Figure 6. Agriculture area

(3.3) Piedmont alluvial: alluvial plains can be divided by land use into 2 zones. The first zone is for agriculture, most plants are rice, corns. The second zone is for residential. According to the survey, kinds of plants depend on each community. Most people plants what they like around their houses. And can be put into 4 categories as details below.

1) Fruits, for food or sell such as, mangoes, coconuts, jackfruits, litchis, rambutans, longans, starfruits, bananas.

2) Home - grown vegetables for food or for sale such as, galangals, lemongrasses, peppers, eggplants, papayas.

3) Flowering and ornamental plants, for decorations such as, bougainvillea, ixora, orange trumpets, pines, starburst bushes and betel nuts. 


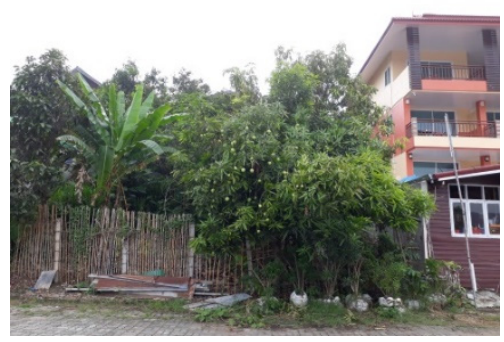

Figure 7. Plants that are found around community

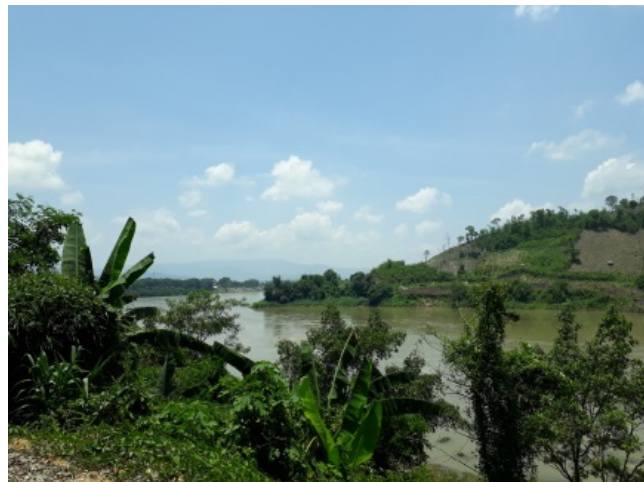

Figure 9. Plants along Mae-Khong riverside

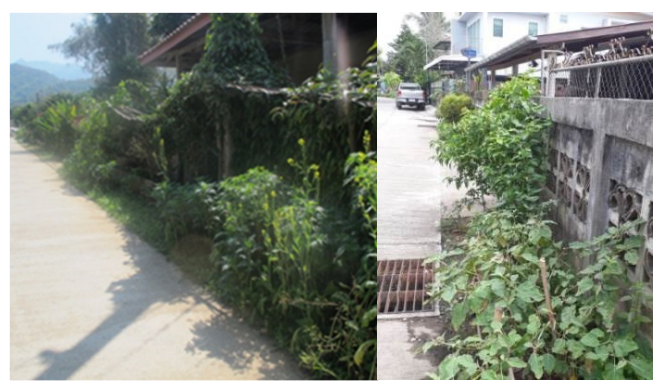

Figure 8. Decorating landscape with local vegetables

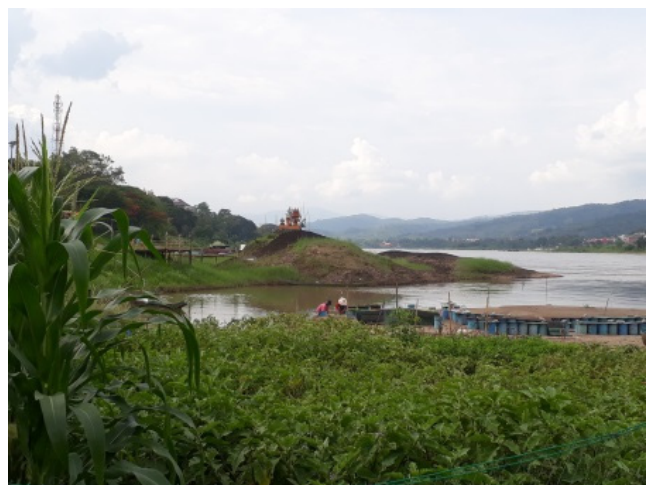

Figure 10. Mae-Khong riverside agriculture

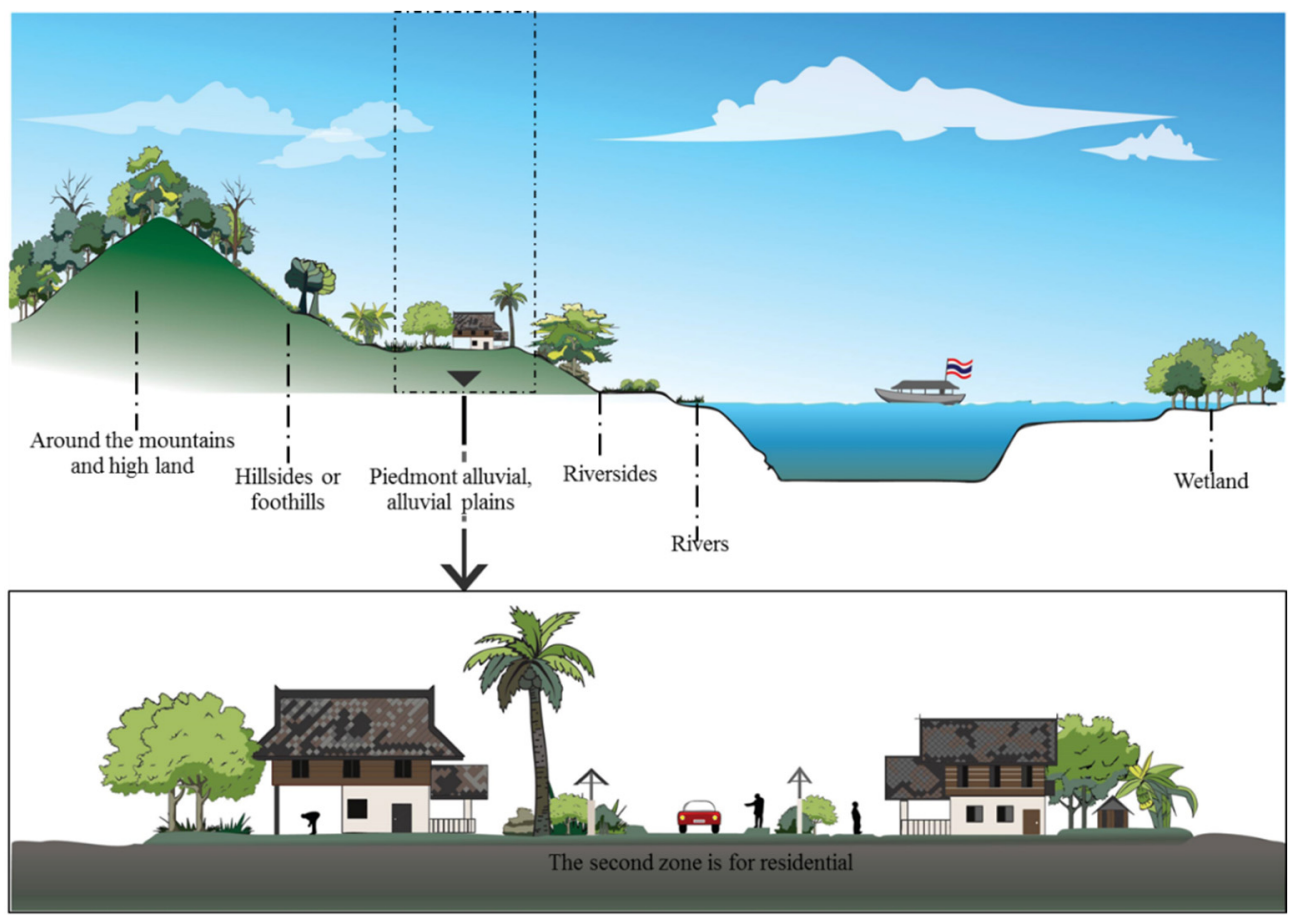

Figure 11. Kinds of plants in ChiangKhong that are related to landscape or area

4) Plants for using at ceremonies or plants for good fortune such as, cape jasmine, marigolds, globe amaranths. And sacred plants that related to people's belief are for decoration as bringing good fortune and support better life to those who planted it such as star gooseberry trees, morinda citrifolia trees, jackfruit trees and other kinds of hemps and herbs. They also plant it according to their belief of lucky directions. 
Moreover, planting organic vegetables has been promoted in each community. This to support healthy lifestyle and bring good image to each community as they neatly and beautifully plant them around their houses. Most vegetables are lettuces, cabbages, kales, onions, garlics, and loofah.

(4) Riversides: including some which are river bank. Most plant are bananas, paper mulberries and white popinac. And some areas caused by dreg from the river makes river plain or during the season that Mae-Khong river reaches the low water level season and reveals beach. This area is used as "Mae-Khong riverside agriculture". Thus, most plants around this area are mostly vegetables for agriculture such as, corns, eggplants, peppers, string beans, local vegetables, tobacco leaves, bean sprouts on sand from Ma-Khong river.

(5) Wetland is not only being detention basin or Kame Ling for preserving water, but also an important ecology and area for local people to find food. Most of the area covers Khrueng and Bun Rueang sub-district. The area is wetland forest and most plants found in that region are rain trees, bamboos and local herbs.

(6) Rivers, there is seaweed called Gai or cladophoa in the Mae Khong river. Local people make food processing for eating and selling. It's one of the famous products from Chiang Khong.

\section{Cultural Factors}

\section{(1) Rehabilitation / Occupations}

The areas for studying this research used to be a community originating from the past period. In Wiang sub-district (Wiang Chiang Khong Archeological Site), there is the ditch with 2 layers ridges around it, is located along the direction from north to south. On the east side is located near the Mae-Khong river. On the west side is a low plain and mountain range (Office of Natural Resources and Environmental Policy and Planning, 2014, pp.2-92,2-93). And the small canal in the north side is connected to the Mae-Khong river. And in Sathan sub- district (Muang Nam Archeological Site), there is also the ditch with 2 layers ridge. The city map is in 2 oval shapes which are connected to each other, located along the direction from north to south. Those evidences show the ancient city plan (Office of Natural Resources and Environmental Policy and Planning, 2004, p.93).

With differences landscapes such as, mountains, rivers, and low plains that suitable for a living, people built communities according to their occupations that are suitable to each landscape. They can be divided into 3 groups as detailed below (Ninjang as cited in Limthongsakun,2006, p.146).

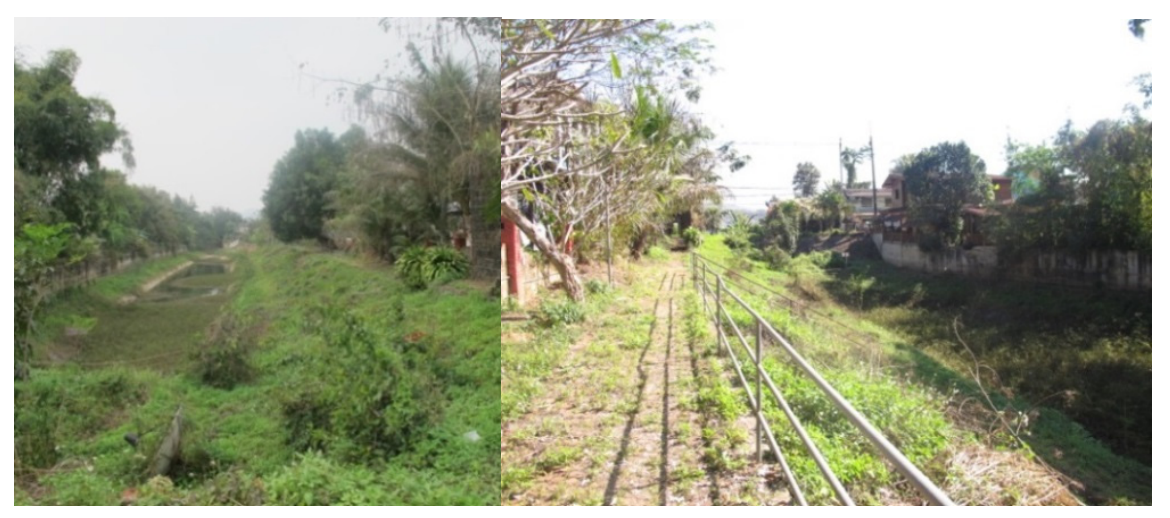

Figure 12. The canal in Wiang sub- district nowadays is a proof that there had been community since past period

1) The alluvial plain community along the Mae-Khong and Ing river: The pattern of the community is liner along with the river. There are several routes from the village to the rivers. In the past, this area used to be an important spot for water transportation. Villagers use the rivers for local fishing, agriculture, and also sea freight. There was soil improvement according to environment change, social changes and economic changes. In the past people lived along the Mae-Khong river but recently have also become a trading city as the outpost connected to Laos for trading (Sukkay et al., 2016, p.339). Fishing and fishermen has been reduced. But there is fishing by using floating baskets for selling instead. And tourism business has expanded. There are more hotels or guest houses for tourists in some areas along the Mae-Khong river. For the community that is further away from the river, houses are still situated along the roads. Most people in this area merchants or service officers. 
2) Low plain community: the pattern of the community is clustered along transportation routes and as a liner along the roads. Houses are built and gathered in the area that is closer to the city. Most occupations are merchants and agriculturists. A bit further away is an abundance area with good irrigation, houses in this area are spread out not gather, but more like homestead. Most occupations are farmers, owning fruit gardens, mixed agriculture and handcrafting such as weaving, basketry.

3) Highland or foothill community. The pattern of the community is clustered. Most people are farmers such as, corn farm, pineapple farm and fruit farm. Also, handcrafting such as, weaving for each style of each ethnic groups, woodwork and basketry.

The main reasons of habitation are the ability to use soil resource and plentiful water, that can support people's lives in the community, including being able to connect to other places outside the community (Ninjang as cited in Limthongsakun,2006, p.146). We can see from houses along the Mae-Khong and Ing rivers, it was the main transportation routes in the past. And the area must have had plenty of food to be able to provide nourishment to the community. Road construction plans can be seen in the community map. And when land transportation become more important, people started building houses along the roads.

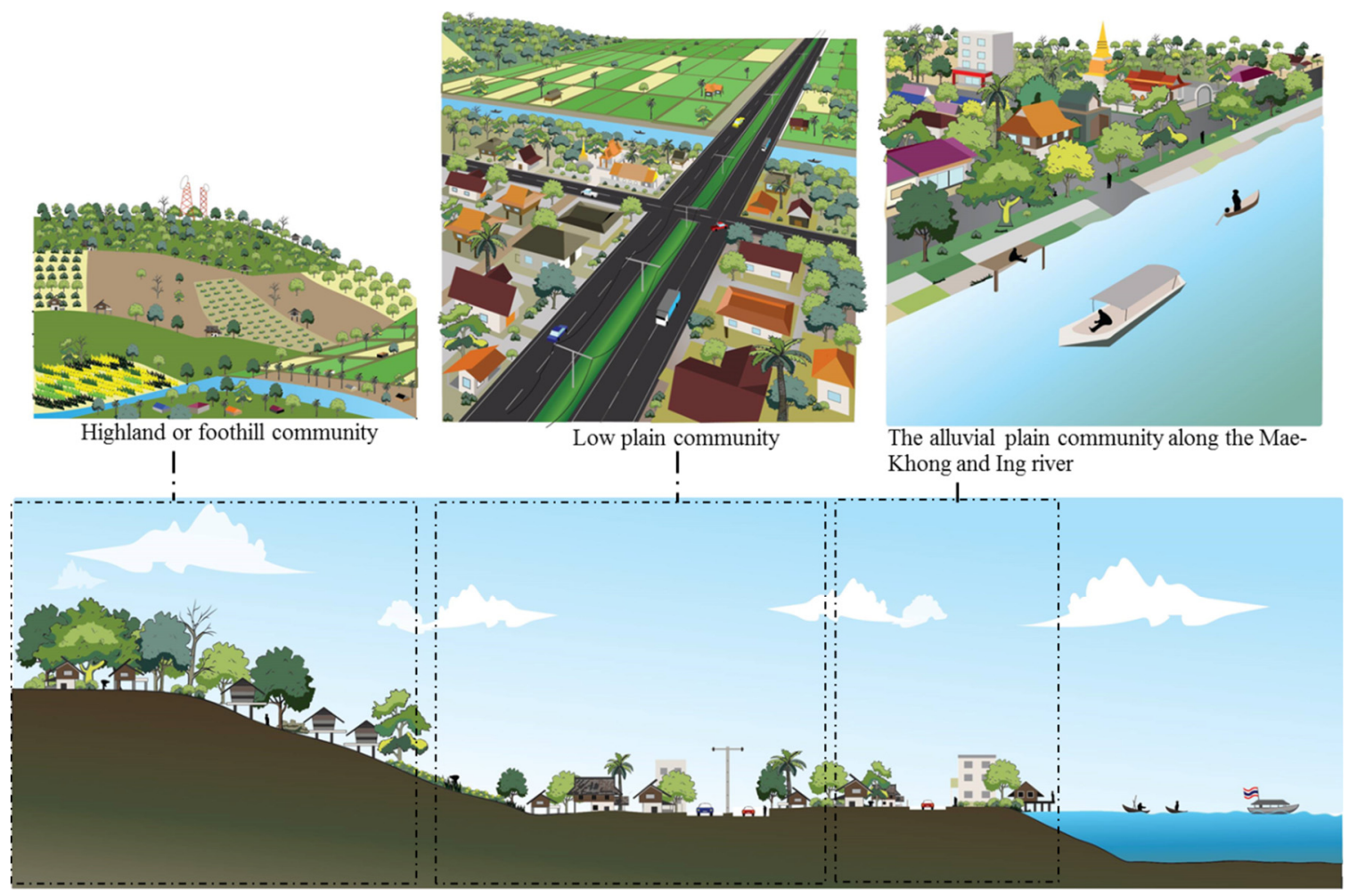

Figure 13. Habitation forms that are related to occupations in ChiangKhong areas

From past studies it was found out that people from the villages or in community have been using land as for housing area, service area, religion area, trading area, group activities area, tourism area, and agriculture area. The physical outstanding from each area can be seen as they are trying to create green front yards in each house by using local plants or vegetables both for food and decorations. We can see this in every community in ChiangKhong.

(2) Lifestyle, culture, tradition and belief

ChiangKhong is named "the City of Mae-Khong Rivers" (Anonymous. 2017, p.2) with abundance ecology, people are from different ethnic groups and most people are Buddhists (Nantasiri et al., 2017, p.11). Those 3 assets taken play important roles in people's lifestyle, culture, tradition and belief combined together. The study found that people in ChiangKhong are connected to the Mae-Khong river both directly and indirectly such as, agriculture during low tide, local fishing, using riverside area for recreation and community activities, including promoting beautiful landscape for tourism. Moreover, people earn money from natural resource from the Mae-Khong river 
which is cladophora (Gai). It is rare and hard to find in other areas in Thailand. The Mae-Khong river is also connected to people's belief that represent the tradition such as Sacrifice Godfather Mae-Khong giant catfish ceremony. The ceremony is held annually on the 18th of April (Anonymous. 2017, p.11), before catfish fishing season from April to late May. This to encourage fishermen to be able to catch the catfish in the river successfully. And also the myth of "King of Nagas", beliefs about King of Nagas in Thai society are found that the king of Nagas is half animal and half Deva with supernatural power to transform themselves to be human or animals. Besides, the king of Nagas is a symbol of water and abundance. Nagas can give benefits such as curing the sickness, giving good luck, and maintaining Buddhism. But, for the bad effect, Nagas can make people sick, and block various ceremonious activities (Namkan,2012). We can see Nagas statues around arches, steps or around temples. For Buddhism, each community has temple as ceremony center. People like doing good deeds both in regular days and important religious days. The temples were designed in relation to religion and beauty in Lanna style, can be found only in the north of Thailand. With a population of not less than 9 ethnic groups, not only will they have lifestyle, culture and tradition like Lanna, there are also unique traditions that they maintain from their ancestors such as food, clothes, languages, architecture design, ceremonies such as, Mong's New Year, sewing and presenting a set of yellow robes for monks ceremony (Tai Lue), Ghost feeding, including handicraft like Tai Lue weaving, tribesman's stitching pattern, making special flags called Tung, basketry and woodwork.

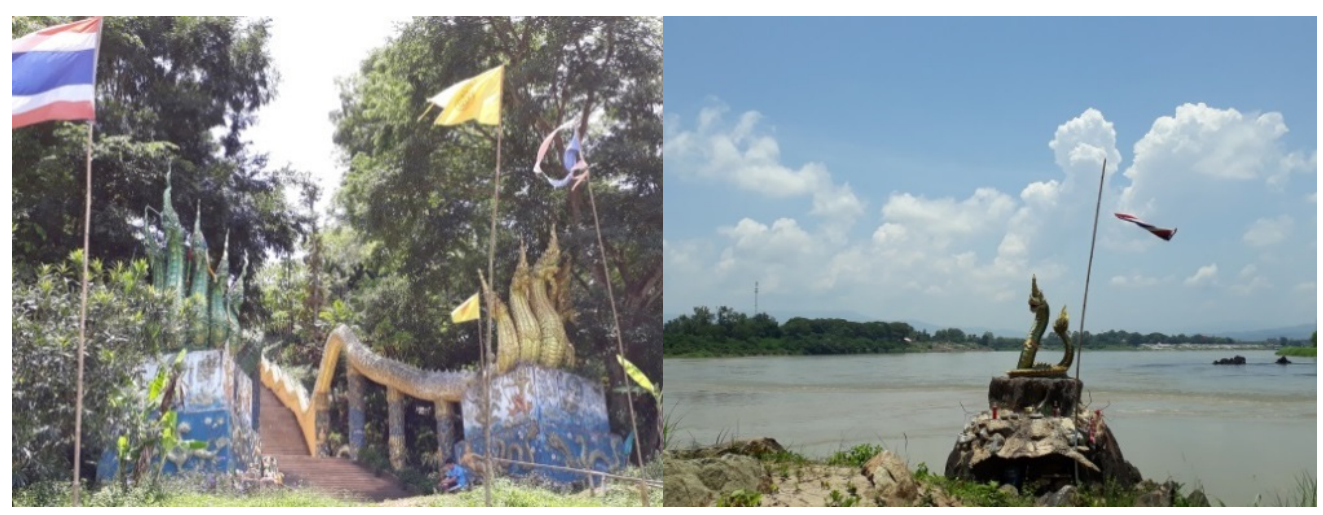

Figure 14. Naga's statue shows that people in the community have a belief
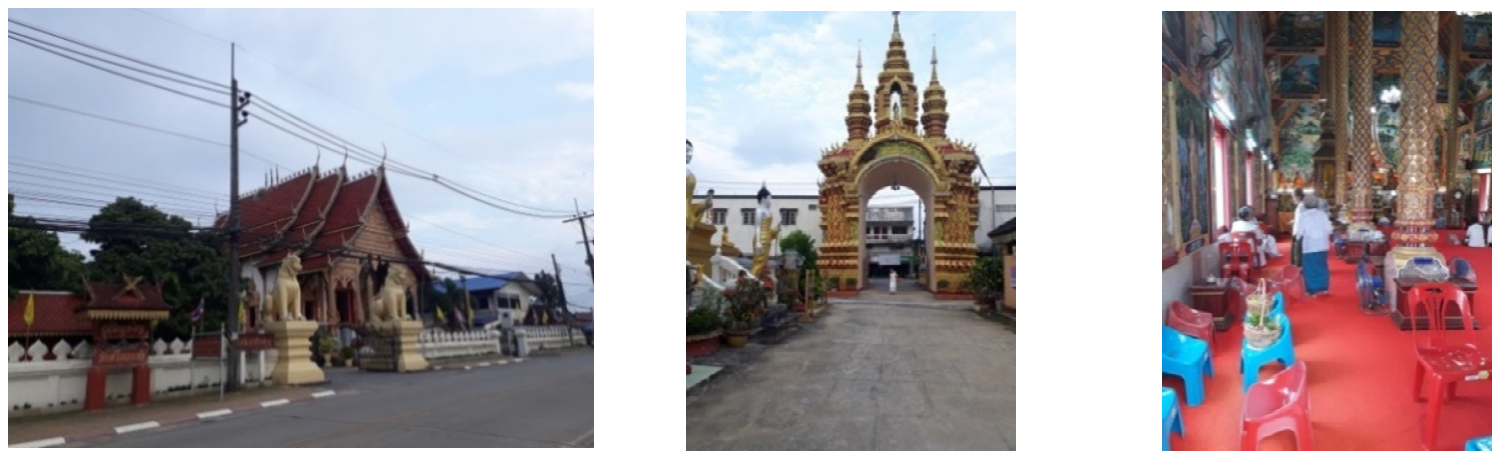

Figure 15. Buddhism temple with Lanna architecture design

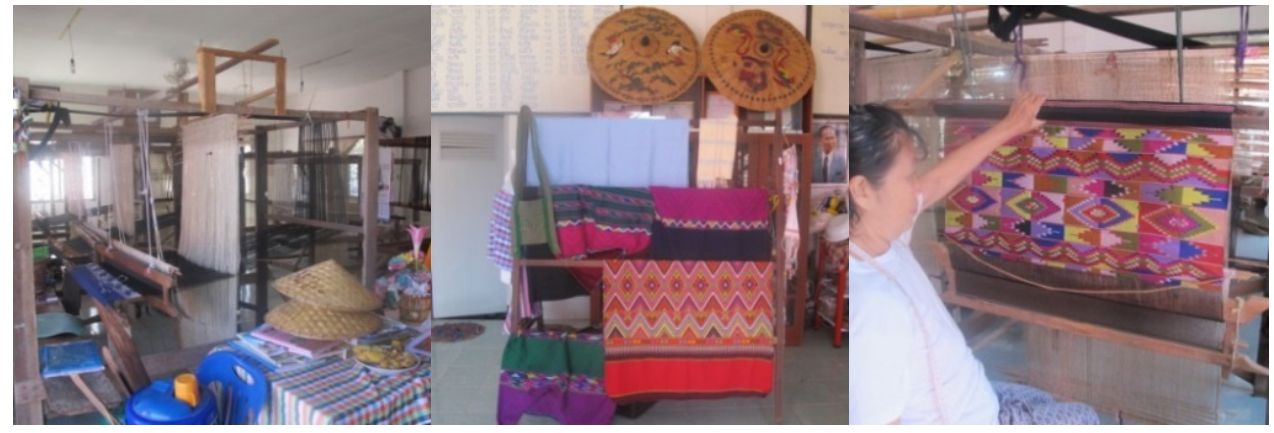

Figure 16. Tai Lue's weaving pattern 


\subsection{The roles of the vernacular landscape for promoting and developing tourism in ChiangKhong in the present}

The study found that by using the vernacular landscape in ChiangKhong to promote and develop tourism can be divided to 3 usage categories which include using original assets, by applying or improving original assets, and by creating new activities, new forms of landscapes which are hardscape and softscape. There are 2 roles of the vernacular landscape which are:

(1) The role that effects promoting and developing tourism directly. It is to bring out local landscape and make it more interesting to tourism industry such as creating tourist attractions or landmark from the myth or belief, making the giant catfish that is famous into special symbols, planting golden trumpet trees along the roads to create activity during tourism season.

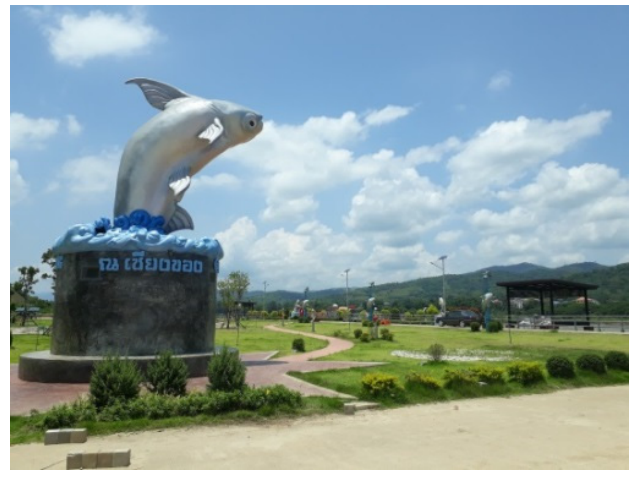

Figure 17. Giant catfish

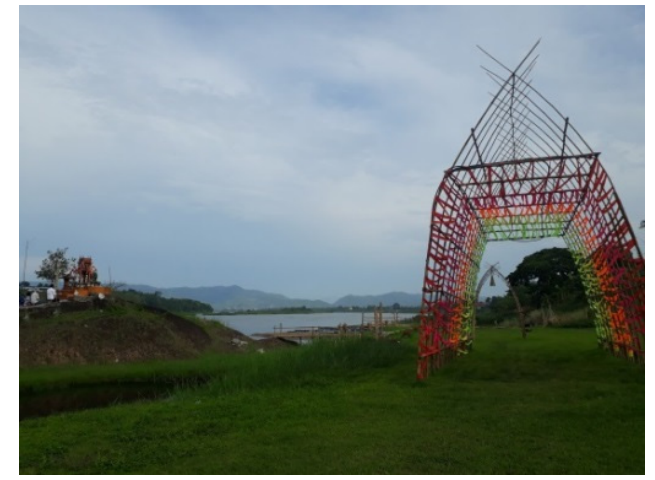

Figure 18. Creating landmark in vernacular landscape

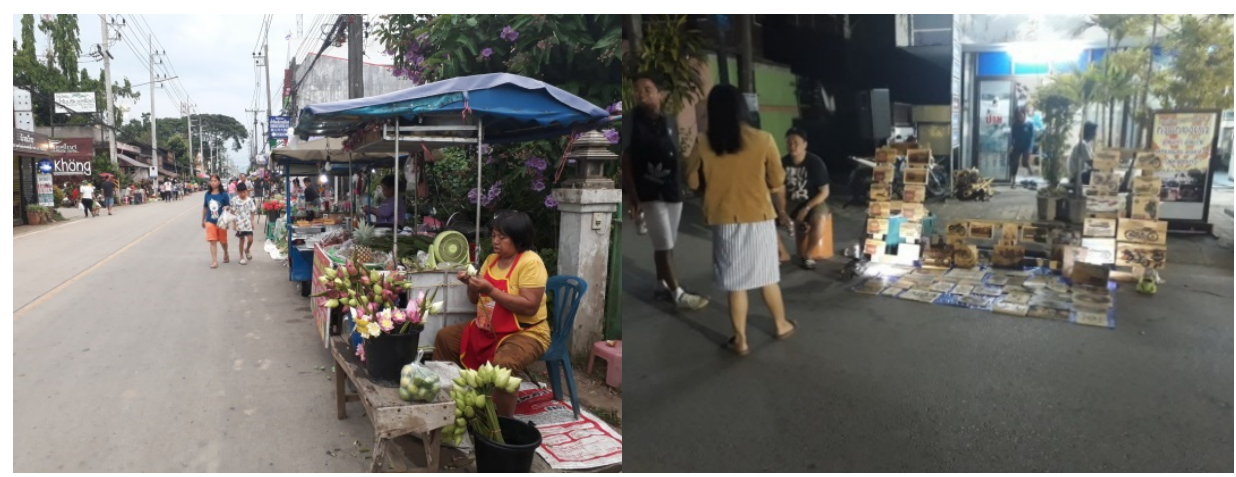

Figure 19. Buddhism temple with Lanna architecture design

(2) Indirect role is original or ordinary lifestyle in the community that's new for other people to see. It can support tourism such as, simple lifestyle, religion ceremony and belief, food, unique clothing, handicraft that is passed by ancestors, different landscape and natural beauty. All these mentioned above can be summarized as in the table 1 .

(3) In- depth interview of two groups of people who are related to the areas.

Interview to two groups of people who are related to those areas about Chiang khong's landscape in 3 issues which are,

1) How does the vernacular landscape identity look like?

2) Which system represents ChiangKhong?

3) The vernacular landscape roles for the ChiangKhong tourism development and support in the present.

From the interview, the interviewer found that the interviewees had both the same opinions and different opinions. As details below in Table 2 . 
Table 1. Shows The roles of the vernacular landscape for promoting and developing tourism in the present ChiangKhong

\begin{tabular}{|c|c|c|c|c|}
\hline \multirow{2}{*}{$\begin{array}{l}\text { Vernacular } \\
\text { Landscape }\end{array}$} & \multirow[t]{2}{*}{ Activities/Landforms } & \multicolumn{2}{|c|}{ Roles } & \multirow[t]{2}{*}{ Promoting and developing tourism } \\
\hline & & Direct & Indirect & \\
\hline \multirow{4}{*}{$\begin{array}{l}\text { 1. Using original } \\
\text { assets }\end{array}$} & Varieties of landscapes & & $\sqrt{ }$ & $\begin{array}{l}\text { Natural beautiful landscape such as, } \\
\text { mountains and rivers }\end{array}$ \\
\hline & $\begin{array}{l}\text { People's lifestyle, culture, tradition, } \\
\text { ceremonies , Activities }\end{array}$ & & $\sqrt{ }$ & $\begin{array}{l}\text { Living museum, } \\
\text { Colors of activities and people }\end{array}$ \\
\hline & Belief & & $\sqrt{ }$ & $\begin{array}{l}\text { Activities or places that can attract } \\
\text { tourists }\end{array}$ \\
\hline & Varieties of ethnic groups & & $\sqrt{ }$ & $\begin{array}{l}\text { Lifestyle, food, costumes, } \\
\text { Handicraft goods }\end{array}$ \\
\hline \multirow{4}{*}{$\begin{array}{l}\text { 2. Applying or } \\
\text { improving } \\
\text { original assets }\end{array}$} & $\begin{array}{l}\text { Using stories or legendries or names of unique } \\
\text { places }\end{array}$ & $\sqrt{ }$ & & $\begin{array}{l}\text { Create tourist attractions or activities } \\
\text { with stories }\end{array}$ \\
\hline & $\begin{array}{l}\text { Using unique symbol that represents each area } \\
\text { such as, giant catfish and ethnic groups }\end{array}$ & $\sqrt{ }$ & & $\begin{array}{l}\text { Beautiful and interesting and unique } \\
\text { decorations }\end{array}$ \\
\hline & $\begin{array}{l}\text { Bringing our old tradition to create activities } \\
\text { such as; Sacrifice Godfather Mae- khong } \\
\text { giant catfish ceremony, sewing and } \\
\text { presenting yellow robes to monks by Tai } \\
\text { Lue, Mong's New Year ceremony }\end{array}$ & $\sqrt{ }$ & & $\begin{array}{l}\text { Interesting activities and ceremony in } \\
\text { each season }\end{array}$ \\
\hline & $\begin{array}{l}\text { Decorating with local plants such as local } \\
\text { vegetables }\end{array}$ & $\sqrt{ }$ & & Creating the identity to the places \\
\hline \multirow{4}{*}{ 3. New creation } & Creating Landmark and viewpoint & $\sqrt{ }$ & & Tourist attractions, Photography spots \\
\hline & $\begin{array}{l}\text { Creating recreation areas such as; public park } \\
\text { along the river and riversides }\end{array}$ & $\sqrt{ }$ & & New tourist attractions and recreation \\
\hline & $\begin{array}{l}\text { Creating new landscape, such as planting } \\
\text { golden trumpet trees, planting flame trees }\end{array}$ & $\sqrt{ }$ & & $\begin{array}{l}\text { Create festival, create seasonal } \\
\text { tourism }\end{array}$ \\
\hline & $\begin{array}{l}\text { Creating new activities, such as, walking } \\
\text { street, offering food to monks along Mae- } \\
\text { Khong river }\end{array}$ & $\sqrt{ }$ & & $\begin{array}{l}\text { Add activities and make tourism more } \\
\text { vibrant }\end{array}$ \\
\hline
\end{tabular}

Table 2. To summarize the same and different opinions from both groups of the interviewees

\begin{tabular}{|c|c|c|c|}
\hline Issue & The local government officers & The same opinions & Specialists \\
\hline 1 & & $\begin{array}{l}\text { There's a combination of both nature and culture. } \\
\text { Especially, Mae-Kong river, tribes, Buddhism. } \\
\text { Including belief that shows both concrete and } \\
\text { abstract. }\end{array}$ & \\
\hline 2 & Giant cat fish, varieties of plants & Mae-khong river, tribes and landscape & People's way of life, \\
\hline 3 & $\begin{array}{l}\text { Creating mythical stories for each local, } \\
\text { named each local as concrete, also creating } \\
\text { new activities and areas to attract tourists. }\end{array}$ & $\begin{array}{l}\text { Bringing both natural and cultural resources to add } \\
\text { as much value as possible for local people but the } \\
\text { identity of each local still remains. }\end{array}$ & $\begin{array}{l}\text { Using simply lifestyle or } \\
\text { way of life, preserving } \\
\text { cultural ecological areas. }\end{array}$ \\
\hline
\end{tabular}

\section{Discussion and Conclusion}

The identity of vernacular landscape in ChiangKhong occurs by natural factors and cultural factors. Each factor is connected. We can see that natural beauty landscapes, plants, occupations and local activities are influenced by the varieties of landscapes. Also, different climate in each season brings different beauty to each season, affect people's way of life, and promotes different activities along Mae-Khong riverside or even habitation and also occupations and plants. Moreover, people's lives, culture, tradition and belief are influenced by Mae-khong river, varieties of ethnic groups and Buddhism. This influence will be reflected in activities, food, clothes, handicraft, languages, temples or houses architecture design, open spaces for gathering together and holding community activities and ceremonies. Those factors have made the vernacular landscape in ChiangKhong as "Combination" and also have outstanding identity of "Place". 
For the roles of the vernacular landscape for developing and promoting tourism in ChiangKhong in the present, the use of landscape can be divided into 3 usage categories. The first one is using original assets such as; differences of landscapes, people's lifestyle, culture, tradition, belief, activities or places that have been modified. This is called indirect role for promoting and developing tourism, focus on nature and people and tourism is by - product. The second one, is by applying or improving original assets, using well-known and outstanding stories or legendary stories, names of places, local vegetables to create new landscapes such as; giant catfish shaped- lamps, using the name of the village that their lover lives to create activities about love to attract tourists and decorating each community with local vegetables. And the third one is by creating new landscapes but still focusing on blending with the original such as, landmark, viewpoint, creating new activities and recreation areas, creating new tourist attractions. For the 2nd and 3rd roles directly influence the promotion and development of tourism and especially focus on tourism.

The summary of this study is that the vernacular has a very important role in developing and supporting tourism. Both direct and indirect ways. It's been brought to present both concrete (landscape element, symbol, areas and activities) and abstract forms (belief and spiritual). Focus mainly on what's most useful for Chiangkhong people. It is the touchable preservation or development that doesn't ruin the original resources. It's to top-up natural and cultural resources to support and develop tourism. At the same time, to preserve and remain the local identity that's almost faded from the local and the environment nowadays.

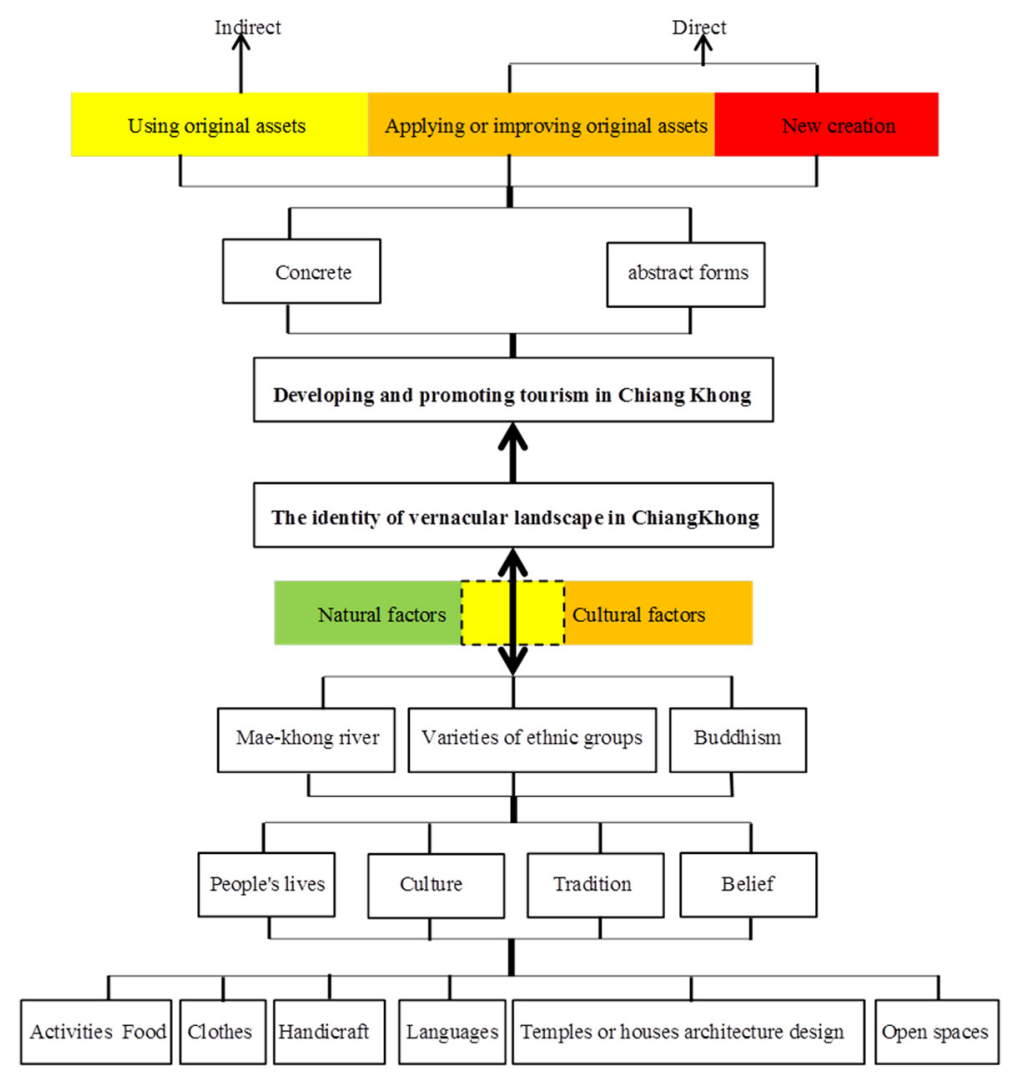

Figure 20. Show that the identity of vernacular landscape in ChiangKhong and the roles of the vernacular landscape for promoting and developing tourism in ChiangKhong in the present

\section{Suggestions}

\section{(1) General suggestions}

Nowadays, by working together both government sector and local people, some tourist attractions in ChiangKhong has brought out the identity of the vernacular landscape quite well. But from observation, some places especially places that hold seasonal or annual festival are neglected. Even though, it appeared on tourist guide books which means tourists can visit any time. So, there should be the process of taking care and keep those place well organized and beautiful all the time. 


\section{(2) Suggestions for the next research.}

There should be study about evaluation of the vernacular landscape element that will help promote tourism in ChiangKhong district.

\section{Acknowledgements}

I greatly appreciate Mr. Tasanai Suthapoj (the Chief District Officer of ChiangKhong), Mr. Phongtawan Nantasiri (A teacher at the Faculty of Architecture, Chiang Rai Rajabhat University), and Mr. Nopparat Lamun (Research Coordinator Facilitator, ChiangKhong Conservation group) for their assistance in conducting the interviews and getting information for the success of the study.

\section{References}

Anambutr, R., Kittiprasan, K., \& Suksawang, W. (2003). Attitude Towards and Preference for Western Vernacular Thai Landscape. Faculty of Architecture, Silapakorn University, Bangkok. 142p.

Anonymous. (2017). Chiang Khong Best Destination. Chiang Rai. 48 p.

Chiang Rai area based strategy economic development plan in Chiang khong: Chiangkong gate to the future. (2017). $60 \mathrm{p}$.

Chotisukhrat, S. (2009). Legend of the Northern City. Nonthaburi: Sripanya Publishing House. 746 p.

Department of Forestry Information. (2018). National Forest. Retrieved from http://forestinfo.forest.go.th

Jongsittipol, T., \& Wongmotha, S. (2015). Economic Strategies to Promoting Border Economic zone: A case study of Chiang Khong, Chiang Rai province. Faculty of Architecture, Khon Kaen University. Homepoom. Wisdom to the Future, 3(1), 73-90.

Lamun, N. (2015). ChaingKhong, One city two type: Green City. Chiang Khong Development for Balancing and Lasting Strategy plan (2015-2019). Chaing Rai. 121p.

Limthongsakul, S. (2006). Vennacular Landscape in Muslim Community of Thailand and Malaysia.Faculty of Architecture and Planning, Thammasat University. Architectural/Planning Research Studies, 4(2), 143-154.

Namkan, V. (2012). A Study of the Influence of Beliefs about King of Nagas Impacts on Thai Society. A Thesis submitted in partial fulfillment of the requirement for the degree of master of arts, Mahachulalongkornrajavidyalaya University, Bangkok.

Nantasiri, P., Sukkay, S., Sermsri, S., Norkaewmool, T., Tancharoenrat, K., \& Lengtrairat, K. (2017). The daptation of Urban Landscape under a Concept of "the System of 1 City 2 Models" in Special Economic Zone Chiang Kong, Chiang Rai Provice. Department of Architectural, Faculty of Industrial Technology, Chiang Rai Rajabhat Univercity. Chiang Rai. 177 p.

Office of Natural Resources and Environmental Policy and Planning. (2014). Final Report: Chapter 2 Current Environment. In Guideline of Strategic Environmental Assessment, Chaing-Rai Special Economic Zone. Retrieved from http://www.onep.go.th/

Sukkay, S., Nantasiri, P., Norkaewmool, T., Tancharoenrat, K., Sermsri, S., \& Lengtrairat, K. (2016). Culture Landscapes Evaluation of Chiang Khong City. Faculty of Architecture, Khon Kaen University. Homepoom. Wisdom to the Future, (3), 333-347.

Siriwong, H. (2015). 9 Ethnic Group Cultural Study and Tourist Information Center, Chiang Khong (Chiang Khong Life Museum). Faculty of Architecture, Sripatum University.

\section{Interviews}

Lamun, N. ChiangKhong Conservation Group (Village's philosopher). (2018, january 30). Interview.

Sutapoch, T. The sheriff of ChiangKhong district. (2018, February 1). Interview.

Nantasiri, P. Lecturer of Architectural, Rajabhat Chiang Rai University. (2018, February 1). Interview.

\section{Copyrights}

Copyright for this article is retained by the author(s), with first publication rights granted to the journal.

This is an open-access article distributed under the terms and conditions of the Creative Commons Attribution license (http://creativecommons.org/licenses/by/4.0/). 